\title{
OSTEOPOROSIS IN FRAIL OLDER ADULTS: RECOMMENDATIONS FOR RESEARCH FROM THE ICFSR TASK FORCE 2020
}

\author{
Y. ROLLAND ${ }^{1}$, M. CESARI ${ }^{2}$, R.A. FIELDING ${ }^{3}$, J.Y. REGINSTER ${ }^{4,5}$, B. VELLAS ${ }^{7}$, A.J. CRUZ-JENTOFT ${ }^{6}$ \\ AND THE ICFSR TASK FORCE
}

1. Service de Médecine Interne et Gérontologie Clinique, Gérontopôle, CHU Toulouse, INSERM 1027, France; 2. IRCCS Istituti Clinici Scientifici Maugeri, University of Milan, Milan, Italy; 3. Tufts University, Boston, MA, USA; 4. Division of Epidemiology, Public Health and Health Economics, University of Liege, Liege, Belgium; 5. Chair for Biomarkers of

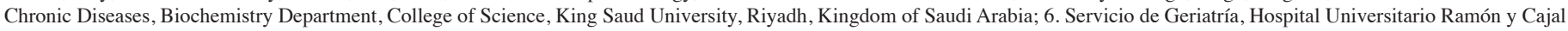
(IRYCIS), Madrid, Spain; 7. Gerontopole, INSERM U1027, Alzheimer's Disease Research and Clinical Center, Toulouse University Hospital, Toulouse, France

Corresponding author: Yves Rolland, Service de Médecine Interne et Gérontologie Clinique, Gérontopôle, CHU Toulouse, INSERM 1027, France, rolland.y@ chu-toulouse.fr

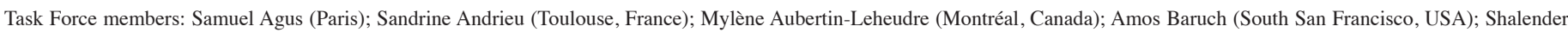

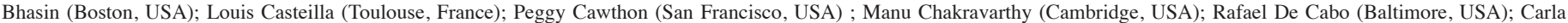

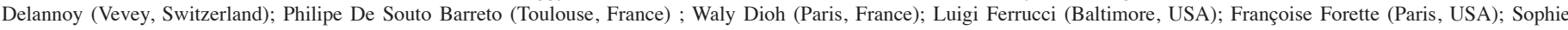

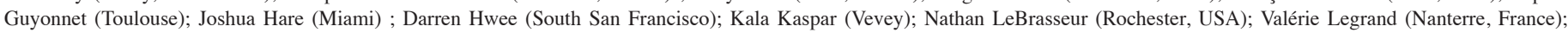

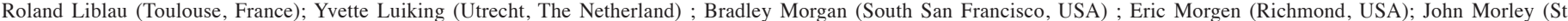

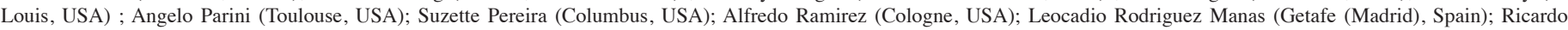

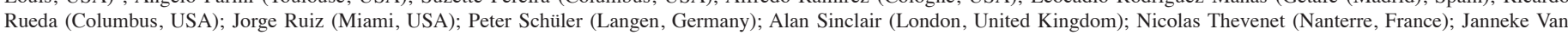
Wijngaarden (Utrecht, The Netherlands); Bruno Vellas (Toulouse, France) ; José Viña (Valencia, Spain); Jeremy Walston (Baltimore, USA); Debra Waters (Dunedin, New Zealand)

\begin{abstract}
Interactions among physiological pathways associated with osteoporosis and sarcopenia are thought to contribute to the onset of frailty. The International Conference on Frailty and Sarcopenia Research Task Force thus met in March 2020 to explore how emerging interventions to manage fracture and osteoporosis in older adults may reduce frailty, disability, morbidity, and mortality in the older population. Both pharmacological and non-pharmacological interventions (including nutritional intervention, exercise, and other lifestyle changes) were discussed, including nutritional intervention, exercise, and other lifestyle changes. Pharmacological treatments for osteoporosis include bone-forming and antiresorptive agents, which may optimally be used in sequential or combination regimens. Since similar mechanisms related to resorption underlie physiological changes in muscle and bone, these interventions may provide benefits beyond treating osteoporosis. Clinical trials to test these interventions, however, often exclude frail older persons because of comorbidities (such as mobility disability and cognitive impairment) or polypharmacy. The Task Force recommended that future clinical trials use harmonized protocols, including harmonized inclusion criteria and similar outcome measures; and that they test a range of multidomain therapies. They further advocated more high-quality research to develop interventions specifically for people who are frail and old. The ICOPE program recommended by WHO appears to be highly recommended to frail older adults with osteoporosis.
\end{abstract}

Key words: Frailty, osteoporosis, prevention, ICOPE.

J Frailty Aging 2021;10(2)168-175

Published online February 7, 2021, http:/ / dx.doi.org/10.14283/jfa.2021.4

\section{Introduction}

All organisms show biologically driven declines in motor function as they age and these declines are closely linked to mortality $(1,2)$. In humans, these declines manifest as the frailty syndrome, which is defined by the overlapping characteristics of low physical activity, slowed motor performance, weakness, fatigue or exercise intolerance, and unintentional weight loss (3). Physiologically, frailty reflects a lowered resistance to stressors resulting from multi-systemic decline. Clinically, frailty is associated with diagnoses of sarcopenia, the age-related loss of muscle mass and strength, and osteoporosis, the loss of bone mass and the deterioration of bone tissue (4). When they occur together, the syndrome may be referred to as "osteosarcopenia" (5). Moreover, interactions between bone and muscle through multiple physiological pathways, including hormonal and inflammatory pathways, are thought to result in the frailty syndrome (6).
As it has done every year since 2014 , the International Conference of Frailty and Sarcopenia Research (ICFSR) Task Force brought together researchers from academia and industry to discuss challenges and opportunities for managing frailty and sarcopenia. In 2020 the Task Force met in Toulouse, France, where it focused attention on emerging interventions to manage fracture and osteoporosis in frail older adults. This population group has often been excluded from recent osteoporosis drug trials due to comorbidities and polypharmacy, despite the fact that they may potentially benefit more from a treatment since they are more likely to have falls, fractures, disability and a poor prognosis.

\section{Associations of frailty with osteoporosis, fragility fracture, and malnutrition}

Bone fragility caused by osteoporosis occurs commonly in older adults and results in increased risk of fragility fracture 


\section{THE JOURNAL OF FRAILTY \& AGING}

(7). A systematic review of worldwide studies estimated that 9 million osteoporotic fractures occurred in 2000, resulting in substantial disability, morbidity, and mortality (8). However, osteoporosis may not be diagnosed until an individual has experienced multiple fragility fractures; and studies show that after diagnosis, treatment for osteoporosis is not routinely given in older adults and adherence to medical regimens is poor (9).

One of the most common and disabling fractures sustained by older persons is hip fracture, which may result in long-term mobility impairment, reduced ability to care for oneself or participate in everyday activities, pain, anxiety, and depression (10). Nutrition plays an important role in bone health and sarcopenia $(11,12)$, and malnutrition is common in individuals with hip fracture (13). Sarcopenia is also associated with an increased rate fractures in older adults $(14,15)$.

Most patients with hip fracture complain of pain and resulting functional limitations six months after the fracture (16), which can lead to a vicious cycle of self-medication and mistrust of clinicians (17). Recovery from hip fracture may be delayed in the presence of sarcopenia (18), and hip fracture may be particularly disabling in individuals with frailty (19). Nearly 30 years ago, Marottoli and colleagues showed that physical function before the fracture predicts functional recovery (20). Comorbidities, fear of falling, and other age-related conditions may further exacerbate hip fracture and its associated functional consequences $(21,22)$. Moreover, individuals over age 80 years, in addition to meeting the frailty phenotype proposed by Fried and colleagues (i.e., weight loss, fatigue, slow gait speed, weakness, sedentary lifestyle), often live alone, and often experience cognitive decline (23); thus they need special management for frailty. However, frail older persons are often excluded from clinical trials of fragility fracture interventions, in part because of comorbidities, sarcopenia, cognitive impairment, and polypharmacy (24).

The substantial impact of fragility fractures on functioning in frail older persons thus requires dedicated and multidisciplinary care pathways, which have been shown to improve quality of life and physical function and limit excessive costs $(25,26)$. Intensive interventions including exercise and physical therapy immediately following hip fracture is essential. Preventive strategies also need to be widely implemented, including early identification of those at risk, increased prescribing of bone loss prevention treatments, and the introduction of care models based on the comprehensive geriatric assessment and personalization of interventions. Recently multidisciplinary, evidence-based guidelines for the management of osteoporosis and fragility fractures have been published (27-29).

Given the association of poor nutrition with sarcopenia and frailty $(30,31)$, assessment of the nutritional status of older adults provides a potential pathway to interventions that could delay or prevent these disabling conditions of aging (32). The Mini Nutritional Assessment (MNA) is a tool designed to rapidly assess nutritional status though a series of simple measurements and brief questions (33). The MNA has been validated in frail older persons (34) and in community-dwelling older adults, demonstrating that frailty and malnutrition are distinct but related conditions (35-37).

Using the MNA short form (MNA-SF), investigators showed that poor nutrition in combination with frailty was associated with an increased prevalence and incidence of poor functional outcomes in the Singapore Longitudinal Aging Study (32). In cancer patients, a low MNA score combined with a high Groningen Frailty Index (GFI) score was associated with an increased mortality risk (38). MNA score has also been used as a prognostic factor of adverse outcomes after hip fracture (39). Yet while there is mounting evidence about the importance of stratifying research populations for frailty, impaired nutritional status at baseline has been associated with greater benefits from the interventions $(40,41)$. The new ESPEN guidelines on the treatment of malnutrition in older people include a section on hip fracture, with the recommendation to incorporate nutrition intervention into a multidisciplinary approach (42).

As a screening tool in outpatients, the MNA-SF has been shown to have a sensitivity of $71.2 \%$ and specificity of $92.8 \%$ (AUC 0.906 ) for the detection of frailty, and a $45.7 \%$ sensitivity and $78.3 \%$ specificity (AUC 0.687 ) for the detection of prefrailty (43). In hospitalized patients, the MNA-SF predicted frailty with good sensitivity but only marginal specificity (44). There is no evidence that the MNA can be used as an outcome measure in trials.

\section{Pharmacological treatment for osteoporosis, sarcopenia, and frailty}

Better targeting of therapeutic interventions for the management of osteoporosis starts with diagnosis, identification of risk factors, and an assessment of fracture risk (45). The International Osteoporosis Foundation and European Society for Clinical and Economic Aspects of Osteoporosis and Osteoarthritis published guidance for the diagnosis and management of osteoporosis in 2013, and recently updated such guidance (46). Diagnostic criteria for sarcopenia have also been recommended by other different groups. The European Working Group on Sarcopenia in Older People (EWGSOP) published a definition in 2010 and updated it in 2019 based on a better understanding of the condition $(47,48)$; and the ICFSR published guidelines on the management of sarcopenia in 2018 (49). In 2017, sarcopenia also was assigned a diagnostic code in the International Classification of Diseases, Tenth Revision, Clinical Modification (ICD-10-CM) code book, indicating recognition of sarcopenia as a separately reportable disease condition for clinical practice and drug development (50).

A fracture may trigger a downward spiral of recurrent fractures known as the "fracture cascade" (51). A study in Iceland showed that the first fracture dramatically increases the risk of a subsequent fractures, particularly during the first year following the first event and regardless of the site of it. The 
Table 1

Screening Tool for the "Integrated Care for Older Persons" (ICOPE)

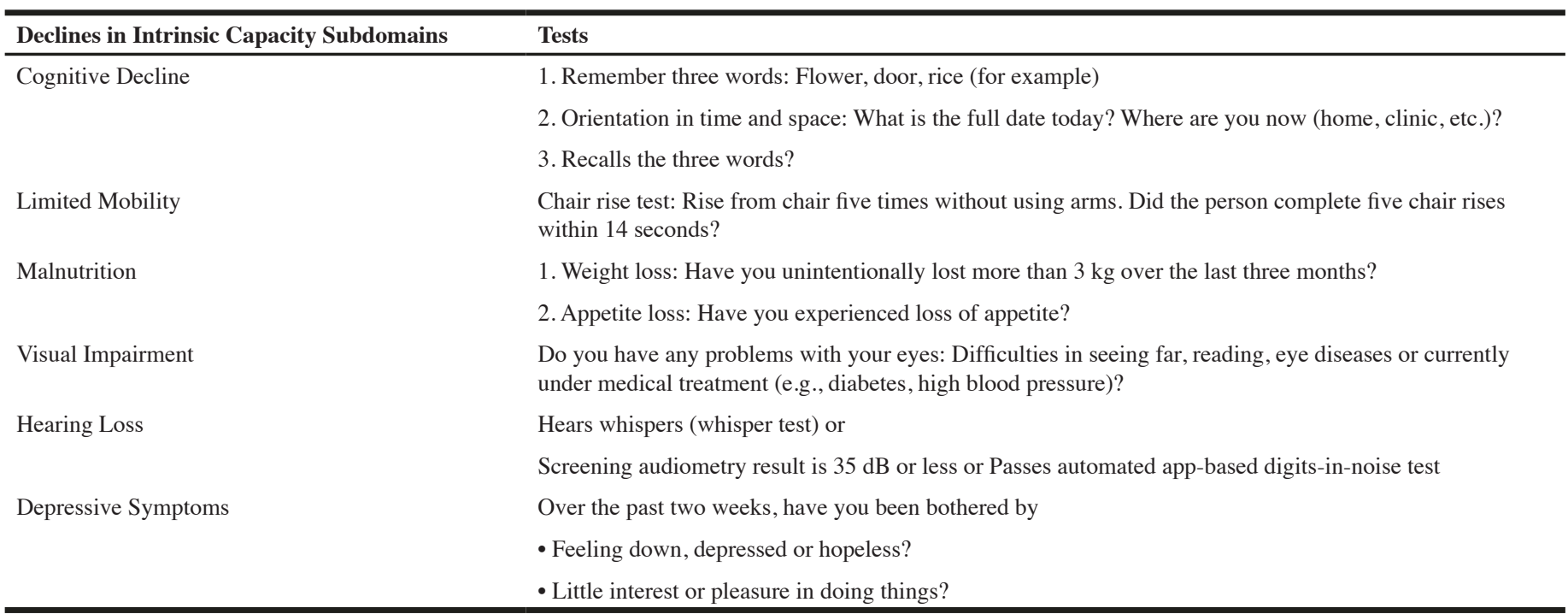

authors concluded that treatment should be started immediately to prevent recurrence of the problem (52). Bone fragility, determined by assessing bone mineral density (BMD) at the hip or spine by DXA scan, is associated with high fracture risk (53), suggesting that restoring bone density may significantly reduce the risk of a second fracture. Low muscle strength and low physical function (sarcopenia) also increase the risk of injurious falls and fractures after a first hip fracture (54).

Several bone-forming drugs are clinically available, including anti-resorptive agents such as denosumab (55-57); romosozumab, a monoclonal antibody that both increases bone formation and inhibits bone resorption $(58,59)$; anabolic agents such as teriparatide (60) and abaloparatide (61-63); biphosphonates such as alendronate and zoledronic acid (64); and myostatin inhibitors, which are also under research as potential drugs to treat sarcopenia $(65,66)$.

Optimal treatment of osteoporosis may require sequential or combination therapies, for example starting with a bone forming agent then add an antiresorptive agent for maintenance. For example, in the phase 2 FRActure study in postmenopausal woMen with ostEoporosis (FRAME), romosuzumab followed by denosumab reduced the risk of fracture in postmenopausal women (67). Other sequential regimens that have shown promise in lowering fracture risk and/or increasing bone density include romosozumab followed by alendronate (68), abaloparatide followed by alendronate $(69,70)$, and combination denosumab/teriparatide followed by denosumab alone (71).

\section{Preventing frailty and its consequences through nutrition and exercise}

The concept of frailty facilitates a better understanding of heterogeneity in the older population and promotes study of the aging process. It provides a possible target for preventive measures aimed at reducing the functional decline and the occurrence of negative events such as falls and fractures (72, 73). Frail patients present with weakness, fatigue, a sedentary lifestyle and mobility impairment. They may have anorexia and recent weight loss. All of these clinical signs increase the risk of falls and fractures. They are also accessible to interventions such as nutritional management and/or physical exercise (focused on strength training and balance), which reduce the risk of falling $(74,75)$.

Several mechanisms responsible for both growth and decline of muscles and bones are shared. It has been hypothesized that pharmacological, nutritional, and/or exercise-based interventions may also overlap and provide mutual/dual benefits (76). For example, both skeletal muscle and bone respond to treatment with androgens, and exercise is an essential element of treatment regimens for osteoporosis, sarcopenia, and frailty. Malnutrition plays an important role in the development of both sarcopenia and frailty (31). Decreased dietary protein intake has been shown to result in decreased lean muscle mass in the Health Aging and Body Composition (ABC) Study (77). The Vitality, Independence and Vigor Study (VIVE2) showed that a high protein, high vitamin D nutritional supplement added to a physical activity intervention led to improvements in muscle density and a loss of intermuscular fat in mobility-limited older adults (78), although these benefits seemed insufficient to improve functional measures such as gait speed (79). Other studies have shown that a combination of resistance exercise and increased protein intake prevented muscle wasting in older adults $(80,81)$.

Obesity is known to contribute to functional declines and frailty in older adults. Sarcopenia in combination with obesity - a condition known as sarcopenic obesity - increases 


\section{THE JOURNAL OF FRAILTY \& AGING}

the risk of functional decline through multiple synergistic pathways. Intervention strategies to combat sarcopenic obesity include weight reduction, calorie restriction, and exercise. Pharmacological strategies may also prove useful (82). Weight reduction through calorie restriction has been shown to have positive effects on longevity, yet it also may result in a loss of fat and lean mass and bone density $(83,84)$. In a study of older frail obese adults, an intervention that combined weight loss and aerobic plus resistance exercise, Villareal and colleagues showed that in comparison to either approach alone, the combination resulted in greater physical function and aerobic capacity and attenuated the loss of bone mineral density $(85$, 86).

The mechanisms by which dietary changes and exercise influence muscle and bone provide clues that may help design better and more targeted intervention strategies. For example, evidence implicates age-related declines in muscle insulin-like growth factor 1 (IGF-1) in sarcopenia; and both exercise and injury increase IGF-1, IGF-1 receptors, and IGF-1 activated signaling pathways. Aging muscle may have less ability to synthesize IGF-1 or may be resistant to IGF-1, and aging may also be associated with attenuation of the ability of exercise to induce IGF-1 (87).

A small study of healthy older women fed with a low-protein diet for 10 weeks showed a decline in both muscle mass and IGF-1 (88). More than 20 years ago, Rizzoli and colleagues showed that protein supplementation in frail individuals post hip fracture restored levels of IGF-1 in the plasma and attenuated loss in bone mineral density compared to placebo (89). Supplementation with selenium and coenzyme Q10 have also been shown to increase levels of IGF-1 in older adults (90).

Skeletal muscle cells express the vitamin D receptor (VDR), and low levels of vitamin D have been associated with lower muscle strength, mobility impairments, and disability (91). In mobility-impaired older women, vitamin D supplementation increased VDR expression and improved skeletal muscle fiber size (92). However, another study in older adults with low baseline levels of serum 25(OH)D showed that while supplementation increased serum levels to more normal levels, there was no effect on lean mass, lower-extremity power, or strength (93).

Nutritional supplements that target inflammation have also been proposed as a strategy for improving muscle function in older adults. For example, omega-3 fatty acids derived from fish oil have also been shown to slow decline in muscle mass and function in older adults (94). However, a recent clinical trial, the ENabling Reduction of low-Grade Inflammation in SEniors (ENRGISE) Pilot study, which tested the efficacy of fish oil and the angiotensin receptor blocker losartan in older, mobility-impaired adults, showed no improvement of walking speed or serum level of the inflammatory marker IL-6 (95).

Demonstrating the efficacy of nutritional interventions is challenging for many reasons, including the difficulty of determining whether the baseline level of dietary intake is inadequate and capturing subtle effects of change from baseline. These challenges are exacerbated when nutritional interventions are superimposed on other interventions.

\section{Designing clinical trials to target bone fracture in frail older adults}

The burden of fracture is expected to increase worldwide as the population ages, yet few trials have assessed the benefit of treatments in the oldest old and even less in the frail population $(96,97)$. Thus, fracture prevention and optimizing bone health represent important public health goals. Interventions that target the frail population offer the potential for the greatest benefit, as was demonstrated in a study by Rolland and colleagues, which tested the ability of strontium ranelate to reduce vertebral fractures in osteoporotic women, independently of frailty status (98). Beyond pharmacological interventions, nutrition and exercise have been shown to act synergistically to improve bone and muscle health and thus should be incorporated into randomized clinical trials (99).

To increase the efficiency and maximizing learnings from clinical studies, sponsors and researchers should use harmonized protocols with similar outcome measures. The ICFSR Task Force suggested the following:

\section{Possible Study Design}

The placebo-controlled, parallel-arm, double-blind trial is the gold standard for assessing efficacy and effectiveness. Other elements of an optimal trial design include:

- A long run-in phase before initiating treatment, during which activity diaries could be monitored and dietary inadequacies or anemia corrected to ensure a stable baseline.

- 2 × 2 designs for studies testing multimodal approaches such as resistance exercise and/or combination of resistance and aerobic exercise and nutrition.

- Using assessment time points that have been harmonized with other studies to enable data pooling and meta-analyses of data.

- Use the gold standard of collecting falls incidence using monthly calendars.

- At least one-year of follow up. If studies aim to target bone fracture or prevent the progression from pre-sarcopenia to sarcopenia, long follow-up will be necessary.

\section{Proposed Outcomes}

- Primary outcome: fragility fractures at 24 months (hip and spine).

- Secondary outcomes:

o Physical performance and disability as measures of functional decline

o Injurious falls

o Patient-reported outcomes, including mobility assessments and quality of life

o Nursing home admissions 


\section{OSTEOPOROSIS IN FRAIL OLDER ADULTS}

o Bone turnover biomarkers

o BMD assessment (hip and spine)

- Exploratory outcomes

o Cognitive function

o Comorbidities

o Survival

Note that Fragility fractures or injurious falls as the primary outcome will require a very large sample size. Benefit of pharmacological treatment has also needed a large sample size.

\section{Potential Target Population}

- Patients with low BMD, high rate of falls (such as $\geq 2$ selfreported falls/year), and frailty.

- Inclusion criteria: $\geq 75$ years old with osteoporosis defined by low BMD, FRAX, and/or history of osteoporotic fracture, and with frailty defined by variable proven predictive of falls (100). Patients in nursing homes and those with dementia should be included where possible.

- Exclusions: Projected life expectancy $<2$ years or estimated glomerular filtration rate $<30 \mathrm{~mL} / \mathrm{min} / 1.73 \mathrm{~m}^{2}$, individuals who are bedridden or who have contraindications related to the drug being tested

\section{Design of Interventions}

Frailty is a complex syndrome requiring multidimensional interventions. Interventions should target two or more risk factors for falls. For example, polypharmacy and some specific medications have been associated with increase fracture risk (101, 102). The European Geriatric Medicine Society (EuGMS) Task and Finish group on Fall-Risk-Increasing Drugs (FRIDs) recently proposed practical recommendation and strategies to reduce the use of FRIDs (103). The increase risk of falls related to the use of psychotropics drugs (104), cardiovascular drugs (105) and other medications (106) is now well-known. As the field of geroscience continues to emerge, it may become possible to target aging itself (107). For example, cellular senescence represents a promising therapeutic paradigm for potentially preventing or even reversing agerelated osteoporosis and simultaneously treating multiple aging comorbidities (108).

Multidomain interventions for preventing falls in older people living in the community typically include physical activity (strength and balance classes with walking practice), and deprescribing. A systematic review and meta-analysis concluded that such multidomain interventions may reduce the rate of falls and recurrent falls, although the impact on fracture reduction has not been clearly demonstrated (109).

To test an osteoporosis drug in combination with a multidomain intervention, four parallel groups are recommended: 1) osteoporosis drug alone, 2) multidomain intervention alone, 3) osteoporosis drug plus multidomain intervention, 4) placebo or active comparator.

The Multidomain Alzheimer's Prevention Trial (MAPT) study is an example of a multidomain trial in frail older adults (110). This three-year, multicenter, randomized, placebocontrolled superiority trial enrolled community-dwelling persons aged 70 or older with spontaneous memory complaints, absence of dementia, and limitations in one instrumental activity of daily living or slow gait speed. They were randomly assigned to one of four groups: 1) a multidomain intervention comprising cognitive training, physical activity, and nutritional counseling plus omega-3 polyunsaturated fatty acids with a total daily dose of $800 \mathrm{mg}$ docosahexaenoic acid and $225 \mathrm{mg}$ eicosapentaenoic acid, 2) the multidomain intervention plus placebo, 3) omega-3 polyunsaturated fatty acids alone, or 4) placebo alone. The trial was registered with ClinicalTrials. gov (NCT00672685).

\section{Conclusions and next steps}

The ICFSR Task Force reached several conclusions. First, it recognized that the traditional care system is inadequate for dealing with complex health disorders of aging such as frailty, where multidisciplinarity is required $(111,112)$. Cognitive impairment is often associated with frailty and must be taken into consideration $(113,114)$. The links between frailty and cognition are now well described (115-117) and integrated care like the ICOPE program have to be promoted to prevent and treat fractures in frail older persons (118-121).

Second, the Task Force suggested that reducing fracture risk among older adults requires first intervening with a powerful agent to restore the strength of bone, and then switching to an anti-resorptive agent to maintain bone health. The need for treatment is especially true after a first major hip fracture. The high cost of many of these drugs imposes a barrier to such an approach and payers will require studies that document efficacy; yet fractures themselves are costly and health economics studies show that bone forming agents are costeffective even over short time periods. Combination therapies were also recommended, not just for treating the bone but for other factors as well, particularly in individuals who are frail. Benefits of these drugs in frail populations with high risk of fracture, short life expectancy, and high risk of adverse events such as nursing home residents should be investigated. One problem is that these frail older adults often take many drugs due to co-morbidities, including cognitive impairment, undernutrition, depression, and loneliness, raising questions about the value of further adding drugs to treat osteoporosis versus decreasing drug consumption in frail older adults. Advances in the field of geroscience may help in the future to answer these questions by introducing new biomarkers and better targeted therapies (122-124).

Third, the Task Force noted that while pathophysiology of bone fracture is the same in frail and non-frail adults, the mechanisms that lead to bone fracture - poor balance, sarcopenia, poor physical performance, sedentary lifestyle, and poor nutritional status - differ. Given these differences, 


\section{THE JOURNAL OF FRAILTY \& AGING}

specific recommendations may be needed for interventions in people who are frail, for example by more routinely adopting multidimensional and comprehensive interventions (125). To develop these interventions, more studies are needed in people who are frail and old. In addition, high-quality research is needed to confirm the role of nutrition in reversing or preventing frailty and adverse outcomes in frail persons $(126,127)$. Moreover the ICOPE program developed by WHO appears to be most useful for the frail older adults with osteoporosis to maintain Intrinsic capacities, monitor functions with ICOPE MONITOR (119) and prevent further disabilities (Table 1).

Acknowledgements: The authors thank Lisa J. Bain for assistance in the preparation of this manuscript.

Conflicts of interest: ACJ reports grants or personal fees from Fresenius Kabi, Abbott Nutrition, Nestlé, Nutricia, Sanofi, and Pfizer, all unrelated to the submitted article. MC is member of Advisory Board for Nestlé.

\section{Ethical Standards: None}

Open Access: This article is distributed under the terms of the Creative Commons Attribution 4.0 International License (http://creativecommons.org/licenses/by/4.0/), which permits use, duplication, adaptation, distribution and reproduction in any medium or format, as long as you give appropriate credit to the original author(s) and the source, provide a link to the Creative Commons license and indicate if changes were made.

\section{References}

1. Dickinson MH, Farley CT, Full RJ, Koehl MA, Kram R, Lehman S. How animals move: an integrative view. Science. 2000 Apr 7;288(5463):100-6.

2. Studenski S, Perera S, Patel K, Rosano C, Faulkner K, Inzitari M, et al. Gait speed and survival in older adults. JAMA. 2011 Jan 5;305(1):50-8.

3. Fried LP, Xue Q-L, Cappola AR, Ferrucci L, Chaves P, Varadhan R, et al. Nonlinear multisystem physiological dysregulation associated with frailty in older women implications for etiology and treatment. J Gerontol A Biol Sci Med Sci. 2009 Oct:64(10):1049-57.

4. Frisoli A, Chaves PH, Ingham SJM, Fried LP. Severe osteopenia and osteoporosis, sarcopenia, and frailty status in community-dwelling older women: results from the Women's Health and Aging Study (WHAS) II. Bone. 2011 Apr 1;48(4):952-7.

5. Kirk B, Al Saedi A, Duque G. Osteosarcopenia: A case of geroscience. Aging Med (Milton). 2019 Sep;2(3):147-56.

6. Greco EA, Pietschmann P, Migliaccio S. Osteoporosis and Sarcopenia Increase Frailty Syndrome in the Elderly. Front Endocrinol (Lausanne). 2019;10:255.

7. Li G, Thabane L, Papaioannou A, Ioannidis G, Levine MAH, Adachi JD. An overview of osteoporosis and frailty in the elderly. BMC Musculoskelet Disord [Internet]. 2017 Jan 26 [cited 2020 Apr 24];18. Available from: https://www.ncbi.nlm.nih.gov/pmc/ articles/PMC5270357/

8. Johnell O, Kanis JA. An estimate of the worldwide prevalence and disability associated with osteoporotic fractures. Osteoporos Int. 2006 Dec;17(12):1726-33.

9. Hiligsmann M, Cornelissen D, Vrijens B, Abrahamsen B, Al-Daghri N, Biver E, et al. Determinants, consequences and potential solutions to poor adherence to antiosteoporosis treatment: results of an expert group meeting organized by the European Society for Clinical and Economic Aspects of Osteoporosis, Osteoarthritis and Musculoskeletal Diseases (ESCEO) and the International Osteoporosis Foundation (IOF). Osteoporos Int. 2019 Nov;30(11):2155-65.

10. Magaziner J, Hawkes W, Hebel JR, Zimmerman SI, Fox KM, Dolan M, et al Recovery from hip fracture in eight areas of function. J Gerontol A Biol Sci Med Sci. 2000 Sep;55(9):M498-507.

11. Cashman KD. Diet, Nutrition, and Bone Health. J Nutr. 2007 Noy 1;137(11):2507S-2512S

12. Beaudart C, Sanchez-Rodriguez $\mathrm{D}$, Locquet $\mathrm{M}$, Reginster $\mathrm{J}-\mathrm{Y}$, Lengelé L, Bruyère $\mathrm{O}$. Malnutrition as a Strong Predictor of the Onset of Sarcopenia. Nutrients [Internet] 2019 Nov 27 [cited 2020 Apr 28];11(12). Available from: https://www.ncbi.nlm.nih. gov/pmc/articles/PMC6950107/
13. Díaz de Bustamante M, Alarcón T, Menéndez-Colino R, Ramírez-Martín R, Otero Á, González-Montalvo JI. Prevalence of malnutrition in a cohort of 509 patients with acute hip fracture: the importance of a comprehensive assessment. European Journal of Clinical Nutrition. 2018 Jan;72(1):77-81.

14. Yeung SSY, Reijnierse EM, Pham VK, Trappenburg MC, Lim WK, Meskers CGM, et al. Sarcopenia and its association with falls and fractures in older adults: A systematic review and meta-analysis. J Cachexia Sarcopenia Muscle. 2019;10(3):485-500.

15. Kirk B, Phu S, Brennan-Olsen SL, Bani Hassan E, Duque G. Associations between osteoporosis, the severity of sarcopenia and fragility fractures in community-dwelling older adults. Eur Geriatr Med. 2020 Jun;11(3):443-50.

16. Sale JEM, Frankel L, Thielke S, Funnell L. Pain and fracture-related limitations persist 6 months after a fragility fracture. Rheumatol Int. 2017 Aug:37(8):1317-22.

17. Gheorghita A, Webster F, Thielke S, Sale JEM. Long-term experiences of pain after a fragility fracture. Osteoporos Int. 2018 May 1;29(5):1093-104.

18. Landi F, Calvani R, Ortolani E, Salini S, Martone AM, Santoro L, et al. The association between sarcopenia and functional outcomes among older patients with hip fracture undergoing in-hospital rehabilitation. Osteoporos Int. 2017;28(5):1569-76.

19. Kua J, Ramason R, Rajamoney G, Chong MS. Which frailty measure is a good predictor of early post-operative complications in elderly hip fracture patients? Arch Orthop Trauma Surg. 2016 May;136(5):639-47.

20. Marottoli RA, Berkman LF, Cooney LM. Decline in physical function following hip fracture. J Am Geriatr Soc. 1992 Sep;40(9):861-6.

21. Kerr C, Bottomley C, Shingler S, Giangregorio L, de Freitas HM, Patel C, et al The importance of physical function to people with osteoporosis. Osteoporos Int. 2017;28(5):1597-607.

22. Ong T, Yong BKA, Shouter T, Shahrokhi N, Sahota O. Optimising bone health among older people with hip fractures and co-existing advanced chronic kidney disease. Eur Geriatr Med. 2020 Jun 1;

23. Fried LP, Tangen CM, Walston J, Newman AB, Hirsch C, Gottdiener J, et al. Frailty in older adults: evidence for a phenotype. J Gerontol A Biol Sci Med Sci. 2001 Mar;56(3):M146-156

24. European Medicines Agency. Reflection paper on physical frailty: Instruments for baseline characterisation of older populations in clinical trials [Internet]. 2015. Report No.: EMA/CHMP/778709/2015. Available from: https://www.ema.europa.eu/en/ documents/scientific-guideline/reflection-paper-physical-frailty-instruments-baselinecharacterisation-older-populations-clinical_en.pdf

25. Talevski J, Sanders KM, Duque G, Connaughton C, Beauchamp A, Green D, et al. Effect of Clinical Care Pathways on Quality of Life and Physical Function After Fragility Fracture: A Meta-analysis. J Am Med Dir Assoc. 2019 Jul;20(7):926.e1-926. e11.

26. Hawley S, Javaid MK, Prieto-Alhambra D, Lippett J, Sheard S, Arden NK, et al Clinical effectiveness of orthogeriatric and fracture liaison service models of care for hip fracture patients: population-based longitudinal study. Age Ageing. 2016 Mar;45(2):236-42.

27. Nuti R, Brandi ML, Checchia G, Di Munno O, Dominguez L, Falaschi P, et al Guidelines for the management of osteoporosis and fragility fractures. Intern Emerg Med. 2019 Jan;14(1):85-102.

28. Lems WF, Dreinhöfer KE, Bischoff-Ferrari H, Blauth M, Czerwinski E, da Silva J, et al. EULAR/EFORT recommendations for management of patients older than 50 years with a fragility fracture and prevention of subsequent fractures. Ann Rheum Dis. 2017 May;76(5):802-10

29. Compston J, Cooper A, Cooper C, Gittoes N, Gregson C, Harvey N, et al. UK clinical guideline for the prevention and treatment of osteoporosis. Arch Osteoporos. 2017 Dec;12(1):43.

30. Landi F, Sieber C, Fielding RA, Rolland Y, Guralnik J, the ICFSR Task Force A. Nutritional intervention in sarcopenia: report from the international conference on frailty and sarcopenia research task force. Journal of Frailty \& Aging. 2018 Dec 1; Frailty Aging 20187(4):247-52.

31. Cruz-Jentoft AJ, Kiesswetter E, Drey M, Sieber CC. Nutrition, frailty, and sarcopenia. Aging Clin Exp Res. 2017 Feb;29(1):43-8.

32. Wei K, Thein FS, Nyunt MSZ, Gao Q, Wee SL, Ng TP. Nutritional and Frailty State Transitions in the Singapore Longitudinal Aging Study. J Nutr Health Aging. 2018;22(10):1221-7

33. Vellas B, Guigoz Y, Garry PJ, Nourhashemi F, Bennahum D, Lauque S, et al. The min nutritional assessment (MNA) and its use in grading the nutritional state of elderly patients. Nutrition. 1999 Feb 1;15(2):116-22.

34. Lilamand M, Kelaiditi E, Cesari M, Raynaud-Simon A, Ghisolfi A, Guyonnet S, et al. Validation of the Mini Nutritional Assessment-Short Form in a Population of Frail Elders without Disability. Analysis of the Toulouse Frailty Platform Population in 2013. J Nutr Health Aging. 2015 May;19(5):570-4.

35. Lorenzo-López L, Maseda A, de Labra C, Regueiro-Folgueira L, Rodríguez-Villamil JL, Millán-Calenti JC. Nutritional determinants of frailty in older adults: A systematic review. BMC Geriatr. 2017 15;17(1):108.

36. Wei K, Nyunt MSZ, Gao Q, Wee SL, Ng T-P. Frailty and Malnutrition: Related and Distinct Syndrome Prevalence and Association among Community-Dwelling Olde Adults: Singapore Longitudinal Ageing Studies. J Am Med Dir Assoc. 2017 Dec 1;18(12):1019-28

37. Verlaan S, Ligthart-Melis GC, Wijers SLJ, Cederholm T, Maier AB, de van de 


\section{OSTEOPOROSIS IN FRAIL OLDER ADULTS}

Schueren MAE. High Prevalence of Physical Frailty Among Community-Dwelling Malnourished Older Adults-A Systematic Review and Meta-Analysis. J Am Med Dir Assoc. 2017 May 1;18(5):374-82.

38. Aaldriks AA, Maartense E, le Cessie S, Giltay EJ, Verlaan H a. CM, van der Geest LGM, et al. Predictive value of geriatric assessment for patients older than 70 years, treated with chemotherapy. Crit Rev Oncol Hematol. 2011 Aug;79(2):205-12.

39. Malafarina V, Reginster J-Y, Cabrerizo S, Bruyère O, Kanis JA, Martinez JA, et al. Nutritional Status and Nutritional Treatment Are Related to Outcomes and Mortality in Older Adults with Hip Fracture. Nutrients. 2018 Apr 30;10(5).

40. Kim CO. Predicting the Efficacy of Protein-Energy Supplementation in Frail Older Adults Living in Community. J Frailty Aging. 2014;3(2):126-31.

41. Luger E, Dorner TE, Haider S, Kapan A, Lackinger C, Schindler K. Effects of a Home-Based and Volunteer-Administered Physical Training, Nutritional, and Social Support Program on Malnutrition and Frailty in Older Persons: A Randomized Controlled Trial. J Am Med Dir Assoc. 2016 01;17(7):671.e9-671.e16.

42. Volkert D, Beck AM, Cederholm T, Cruz-Jentoft A, Goisser S, Hooper L, et al. ESPEN guideline on clinical nutrition and hydration in geriatrics. Clin Nutr. 2019;38(1):10-47.

43. Soysal P, Veronese N, Arik F, Kalan U, Smith L, Isik AT. Mini Nutritional Assessment Scale-Short Form can be useful for frailty screening in older adults. Clin Interv Aging. 2019;14:693-9.

44. Dent E, Visvanathan R, Piantadosi C, Chapman I. Use of the Mini Nutritional Assessment to detect frailty in hospitalised older people. J Nutr Health Aging. 2012;16(9):764-7.

45. Kanis JA, Harvey NC, McCloskey E, Bruyère O, Veronese N, Lorentzon M, et al. Algorithm for the management of patients at low, high and very high risk of osteoporotic fractures. Osteoporos Int. $2020 \mathrm{Jan} ; 31(1): 1-12$.

46. Kanis JA, Cooper C, Rizzoli R, Reginster J-Y, Scientific Advisory Board of the European Society for Clinical and Economic Aspects of Osteoporosis (ESCEO) and the Committees of Scientific Advisors and National Societies of the International Osteoporosis Foundation (IOF). European guidance for the diagnosis and management of osteoporosis in postmenopausal women. Osteoporos Int. $2019 \mathrm{Jan} ; 30(1): 3-44$.

47. Cruz-Jentoft AJ, Baeyens JP, Bauer JM, Boirie Y, Cederholm T, Landi F, et al Sarcopenia: European consensus on definition and diagnosis: Report of the European Working Group on Sarcopenia in Older People. Age Ageing. 2010 Jul;39(4):412-23.

48. Cruz-Jentoft $\mathrm{AJ}$, Bahat $\mathrm{G}$, Bauer $\mathrm{J}$, Boirie $\mathrm{Y}$, Bruyère $\mathrm{O}$, Cederholm $\mathrm{T}$, et al Sarcopenia: revised European consensus on definition and diagnosis. Age Ageing. $2019 \mathrm{Jul} ; 48(4): 601$

49. Dent E, Morley JE, Cruz-Jentoft AJ, Arai H, Kritchevsky SB, Guralnik J, et al International Clinical Practice Guidelines for Sarcopenia (ICFSR): Screening, Diagnosis and Management. J Nutr Health Aging. 2018;22(10):1148-61.

50. Vellas B, Fielding RA, Bens C, Bernabei R, Cawthon PM, Cederholm T, et al Implications of icd-10 for sarcopenia clinical practice and clinical trials: report by the international conference on frailty and sarcopenia research task force. Journal of Frailty \& Aging. 2018 Mar 1;J Frailty Aging 20187(1):2-9.

51. Broy SB. The Vertebral Fracture Cascade: Etiology and Clinical Implications. Journal of Clinical Densitometry. 2016 Jan 1;19(1):29-34.

52. Kanis JA, Johansson H, Odén A, Harvey NC, Gudnason V, Sanders KM, et al. Characteristics of recurrent fractures. Osteoporos Int. 2018 Aug;29(8):1747-57.

53. Kopperdahl DL, Aspelund T, Hoffmann PF, Sigurdsson S, Siggeirsdottir K, Harris TB, et al. Assessment of incident spine and hip fractures in women and men using finite element analysis of CT scans. J Bone Miner Res. 2014 Mar;29(3):570-80.

54. Lloyd BD, Williamson DA, Singh NA, Hansen RD, Diamond TH, Finnegan TP, et al Recurrent and injurious falls in the year following hip fracture: a prospective study of incidence and risk factors from the Sarcopenia and Hip Fracture study. J Gerontol A Biol Sci Med Sci. 2009 May;64(5):599-609.

55. Dempster DW, Chines A, Bostrom MP, Nieves JW, Zhou H, Chen L, et al. ModelingBased Bone Formation in the Human Femoral Neck in Subjects Treated With Denosumab. J Bone Miner Res. 2020 Mar 12;

56. Ferrari S, Libanati C, Lin CJF, Brown JP, Cosman F, Czerwiński E, et al. Relationship Between Bone Mineral Density T-Score and Nonvertebral Fracture Risk Over 10 Years of Denosumab Treatment. J Bone Miner Res. 2019 Jun;34(6):1033-40.

58. McClung MR, Grauer A, Boonen S, Bolognese MA, Brown JP, Diez-Perez A, et al Romosozumab in postmenopausal women with low bone mineral density. N Engl J Med. 2014 Jan 30;370(5):412-20.

59. Cosman F, Crittenden DB, Adachi JD, Binkley N, Czerwinski E, Ferrari S, et al. Romosozumab Treatment in Postmenopausal Women with Osteoporosis. N Engl J Med. 2016 20;375(16):1532-43.

60. Cosman F, Nieves JW, Roimisher C, Neubort S, McMahon DJ, Dempster DW, et al. Administration of teriparatide for four years cyclically compared to two years daily in treatment Naïve and alendronate treated women. Bone. 2019;120:246-53.

61. Watts NB, Hattersley G, Fitzpatrick LA, Wang Y, Williams GC, Miller PD, et al. Abaloparatide effect on forearm bone mineral density and wrist fracture risk in postmenopausal women with osteoporosis. Osteoporos Int. 2019 Jun;30(6):1187-94.

62. McClung MR, Harvey NC, Fitzpatrick LA, Miller PD, Hattersley G, Wang Y, et al. Effects of abaloparatide on bone mineral density and risk of fracture in postmenopausal women aged 80 years or older with osteoporosis. Menopause. 2018;25(7):767-71.

63. Reginster J-Y, Bianic F, Campbell R, Martin M, Williams SA, Fitzpatrick LA.
Abaloparatide for risk reduction of nonvertebral and vertebral fractures in postmenopausal women with osteoporosis: a network meta-analysis. Osteoporos Int. 2019 Jul;30(7):1465-73.

64. Kim TY, Bauer DC, McNabb BL, Schafer AL, Cosman F, Black DM, et al. Comparison of BMD Changes and Bone Formation Marker Levels 3 Years After Bisphosphonate Discontinuation: FLEX and HORIZON-PFT Extension I Trials. Journal of Bone and Mineral Research. 2019;34(5):810-6.

65. Wallner C, Jaurich H, Wagner JM, Becerikli M, Harati K, Dadras M, et al. Inhibition of GDF8 (Myostatin) accelerates bone regeneration in diabetes mellitus type 2. Sci Rep [Internet]. 2017 Aug 29 [cited 2020 May 2];7. Available from: https://www.ncbi. nlm.nih.gov/pmc/articles/PMC5575348/

66. Rooks D, Praestgaard J, Hariry S, Laurent D, Petricoul O, Perry RG, et al. Treatment of Sarcopenia with Bimagrumab: Results from a Phase II, Randomized, Controlled, Proof-of-Concept Study. J Am Geriatr Soc. 2017 Sep;65(9):1988-95.

67. Cosman F, Crittenden DB, Ferrari S, Lewiecki EM, Jaller-Raad J, Zerbini C, et al. Romosozumab FRAME Study: A Post Hoc Analysis of the Role of Regional Background Fracture Risk on Nonvertebral Fracture Outcome. J Bone Miner Res. 2018;33(8):1407-16.

68. Saag KG, Petersen J, Brandi ML, Karaplis AC, Lorentzon M, Thomas T, et al Romosozumab or Alendronate for Fracture Prevention in Women with Osteoporosis. N Engl J Med. 2017 12;377(15):1417-27.

69. Bone HG, Cosman F, Miller PD, Williams GC, Hattersley G, Hu M-Y, et al ACTIVExtend: 24 Months of Alendronate After 18 Months of Abaloparatide or Placebo for Postmenopausal Osteoporosis. J Clin Endocrinol Metab. 2018 01;103(8):2949-57.

70. Cosman F, Miller PD, Williams GC, Hattersley G, Hu M-Y, Valter I, et al. Eighteen Months of Treatment With Subcutaneous Abaloparatide Followed by 6 Months of Treatment With Alendronate in Postmenopausal Women With Osteoporosis: Results of the ACTIVExtend Trial. Mayo Clin Proc. 2017 Feb;92(2):200-10.

71. Leder BZ, Tsai JN, Uihlein AV, Wallace PM, Lee H, Neer RM, et al. Denosumab and teriparatide transitions in postmenopausal osteoporosis (the DATA-Switch study) extension of a randomised controlled trial. Lancet. 2015 Sep 19;386(9999):1147-55.

72. Kojima G. Frailty as a Predictor of Future Falls Among Community-Dwelling Older People: A Systematic Review and Meta-Analysis. Journal of the American Medical Directors Association. 2015 Dec;16(12):1027-33.

73. Dent E, Morley JE, Cruz-Jentoft AJ, Woodhouse L, Rodríguez-Mañas L, Fried LP, et al. Physical Frailty: ICFSR International Clinical Practice Guidelines for Identification and Management. J Nutr Health Aging. 2019;23(9):771-87.

74. Kritchevsky SB, Lovato L, Handing EP, Blair S, Botoseneanu A, Guralnik JM, et al. Exercise's effect on mobility disability in older adults with and without obesity: The LIFE study randomized clinical trial. Obesity (Silver Spring). 2017;25(7):1199-205.

75. Marzetti E, Cesari M, Calvani R, Msihid J, Tosato M, Rodriguez-Mañas L, et al. The "Sarcopenia and Physical fRailty IN older people: multi-componenT Treatment strategies" (SPRINTT) randomized controlled trial: Case finding, screening and characteristics of eligible participants. Exp Gerontol. 2018;113:48-57.

76. Lebrasseur NK, Achenbach SJ, Melton LJ, Amin S, Khosla S. Skeletal muscle mass is associated with bone geometry and microstructure and serum insulin-like growth factor binding protein-2 levels in adult women and men. J Bone Miner Res. 2012 Oct;27(10):2159-69.

77. Houston DK, Nicklas BJ, Ding J, Harris TB, Tylavsky FA, Newman AB, et al. Dietary protein intake is associated with lean mass change in older, community-dwelling adults: the Health, Aging, and Body Composition (Health ABC) Study. Am J Clin Nutr. 2008 Jan;87(1):150-5.

78. Englund DA, Kirn DR, Koochek A, Zhu H, Travison TG, Reid KF, et al. Nutritional Supplementation With Physical Activity Improves Muscle Composition in MobilityLimited Older Adults, The VIVE2 Study: A Randomized, Double-Blind, PlaceboControlled Trial. J Gerontol A Biol Sci Med Sci. 2017 Dec 12;73(1):95-101.

79. Fielding RA, Travison TG, Kirn DR, Koochek A, Reid KF, von Berens Å, et al. Effect of Structured Physical Activity and Nutritional Supplementation on Physical Function in Mobility-Limited Older Adults: Results from the VIVE2 Randomized Trial. J Nut Health Aging. 2017;21(9):936-42.

80. Breen L, Phillips SM. Interactions between exercise and nutrition to prevent muscle waste during ageing. Br J Clin Pharmacol. 2013 Mar;75(3):708-15.

81. Deutz NEP, Bauer JM, Barazzoni R, Biolo G, Boirie Y, Bosy-Westphal A, et al. Protein intake and exercise for optimal muscle function with aging: recommendations from the ESPEN Expert Group. Clin Nutr. 2014 Dec;33(6):929-36.

82. Batsis JA, Villareal DT. Sarcopenic obesity in older adults: aetiology, epidemiology and treatment strategies. Nat Rev Endocrinol. 2018;14(9):513-37.

83. Das SK, Roberts SB, Bhapkar MV, Villareal DT, Fontana L, Martin CK, et al. Bodycomposition changes in the Comprehensive Assessment of Long-term Effects of Reducing Intake of Energy (CALERIE)-2 study: a 2-y randomized controlled trial of calorie restriction in nonobese humans. Am J Clin Nutr. 2017;105(4):913-27.

84. Villareal DT, Fontana L, Weiss EP, Racette SB, Steger-May K, Schechtman KB, et al. Bone Mineral Density Response to Caloric Restriction-Induced Weight Loss or Exercise-Induced Weight Loss: A Randomized Controlled Trial. Arch Intern Med. 2006 Dec 11;166(22):2502-10.

85. Villareal DT, Chode S, Parimi N, Sinacore DR, Hilton T, Armamento-Villareal R, et al. Weight loss, exercise, or both and physical function in obese older adults. N Engl J 


\section{THE JOURNAL OF FRAILTY \& AGING}

Med. 2011 Mar 31:364(13):1218-29.

86. Shah K, Armamento-Villareal R, Parimi N, Chode S, Sinacore DR, Hilton TN, et al. Exercise training in obese older adults prevents increase in bone turnover an attenuates decrease in hip bone mineral density induced by weight loss despite decline in bone-active hormones. J Bone Miner Res. 2011 Dec;26(12):2851-9.

87. Adamo ML, Farrar RP. Resistance training, and IGF involvement in the maintenance of muscle mass during the aging process. Ageing Res Rev. 2006 Aug;5(3):310-31.

88. Castaneda C, Gordon PL, Fielding RA, Evans WJ, Crim MC. Marginal protein intake results in reduced plasma IGF-I levels and skeletal muscle fiber atrophy in elderly women. J Nutr Health Aging. 2000;4(2):85-90.

89. Schürch MA, Rizzoli R, Slosman D, Vadas L, Vergnaud P, Bonjour JP. Protein supplements increase serum insulin-like growth factor-I levels and attenuate proximal femur bone loss in patients with recent hip fracture. A randomized, double-blind, placebo-controlled trial. Ann Intern Med. 1998 May 15;128(10):801-9.

90. Alehagen U, Johansson P, Aaseth J, Alexander J, Brismar K. Increase in insulinlike growth factor 1 (IGF-1) and insulin-like growth factor binding protein 1 after supplementation with selenium and coenzyme Q10. A prospective randomized doubleblind placebo-controlled trial among elderly Swedish citizens. PLoS One [Internet]. 2017 Jun 13 [cited 2020 May 4];12(6). Available from: https://www.ncbi.nlm.nih.gov/ pmc/articles/PMC5469470/

91. Houston DK, Tooze JA, Davis CC, Chaves PHM, Hirsch CH, Robbins JA, et al. Serum 25-hydroxyvitamin D and physical function in older adults: the Cardiovascular Health Study All Stars. J Am Geriatr Soc. 2011 Oct;59(10):1793-801.

92. Ceglia L, Niramitmahapanya S, da Silva Morais M, Rivas DA, Harris SS, BischoffFerrari $\mathrm{H}$, et al. A randomized study on the effect of vitamin $\mathrm{D}_{3}$ supplementation on skeletal muscle morphology and vitamin D receptor concentration in older women. J Clin Endocrinol Metab. 2013 Dec;98(12):E1927-1935.

93. Shea MK, Fielding RA, Dawson-Hughes B. The effect of vitamin D supplementation on lower-extremity power and function in older adults: a randomized controlled trial. Am J Clin Nutr. 2019 01;109(2):369-79.

94. Smith GI, Julliand S, Reeds DN, Sinacore DR, Klein S, Mittendorfer B. Fish oilderived n-3 PUFA therapy increases muscle mass and function in healthy older adults. Am J Clin Nutr. 2015 Jul;102(1):115-22.

95. Pahor M, Anton SD, Beavers DP, Cauley JA, Fielding RA, Kritchevsky SB, et al Effect of Losartan and Fish Oil on Plasma IL-6 and Mobility in Older Persons. The ENRGISE Pilot Randomized Clinical Trial. J Gerontol A Biol Sci Med Sci. 2019 Sep 15;74(10):1612-9.

96. Cole ZA, Dennison EM, Cooper C. Osteoporosis epidemiology update. Curr Rheumatol Rep. 2008 Apr;10(2):92-6.

97. Cooper C, Campion G, Melton LJ. Hip fractures in the elderly: a world-wide projection. Osteoporos Int. 1992 Nov;2(6):285-9.

98. Rolland Y, Abellan Van Kan G, Gillette-Guyonnet S, Roux C, Boonen S, Vellas B. Strontium ranelate and risk of vertebral fractures in frail osteoporotic women. Bone. $2011 \mathrm{Feb} ; 48(2): 332-8$.

99. Laskou F, Dennison E. Interaction of Nutrition and Exercise on Bone and Muscle. Eur Endocrinol. 2019 Apr;15(1):11-2.

100. Sambrook PN, Cameron ID, Chen JS, Cumming RG, Lord SR, March LM, et al. Influence of fall related factors and bone strength on fracture risk in the frail elderly. Osteoporos Int. 2007 May; 18(5):603-10.

101. Lai S-W, Cheng K-C, Lin C-L, Liao K-F. Furosemide use and acute risk of hip fracture in older people: A nationwide case-control study in Taiwan. Geriatr Gerontol Int. 2017 Dec;17(12):2552-8.

102. Torstensson M, Hansen AH, Leth-Møller K, Jørgensen TSH, Sahlberg M, Andersson $\mathrm{C}$, et al. Danish register-based study on the association between specific cardiovascular drugs and fragility fractures. BMJ Open. 2015 Dec 29;5(12):e009522.

103. Seppala LJ, van der Velde N, Masud T, Blain H, Petrovic M, van der Cammen TJ, et al. EuGMS Task and Finish group on Fall-Risk-Increasing Drugs (FRIDs): Position on Knowledge Dissemination, Management, and Future Research. Drugs Aging. 2019;36(4):299-307.

104. Seppala LJ, Wermelink AMAT, de Vries M, Ploegmakers KJ, van de Glind EMM, Daams JG, et al. Fall-Risk-Increasing Drugs: A Systematic Review and MetaAnalysis: II. Psychotropics. J Am Med Dir Assoc. 2018;19(4):371.e11-371.e17.

105. de Vries M, Seppala LJ, Daams JG, van de Glind EMM, Masud T, van der Velde N, et al. Fall-Risk-Increasing Drugs: A Systematic Review and Meta-Analysis: I. Cardiovascular Drugs. J Am Med Dir Assoc. 2018;19(4):371.e1-371.e9.

106. Seppala LJ, van de Glind EMM, Daams JG, Ploegmakers KJ, de Vries M, Wermelink AMAT, et al. Fall-Risk-Increasing Drugs: A Systematic Review and Meta-analysis: III Others. J Am Med Dir Assoc. 2018;19(4):372.e1-372.e8.
107. Tchkonia T, Zhu Y, van Deursen J, Campisi J, Kirkland JL. Cellular senescence and the senescent secretory phenotype: therapeutic opportunities. J Clin Invest. 2013 Mar;123(3):966-72.

108. Khosla S, Farr JN, Kirkland JL. Inhibiting Cellular Senescence: A New Therapeutic Paradigm for Age-Related Osteoporosis. J Clin Endocrinol Metab. 2018 01;103(4):1282-90.

109. Hopewell S, Copsey B, Nicolson P, Adedire B, Boniface G, Lamb S. Multifactorial interventions for preventing falls in older people living in the community: a systematic review and meta-analysis of 41 trials and almost 20000 participants. Br J Sports Med. 2019 Aug 21;

110. Andrieu S, Guyonnet S, Coley N, Cantet C, Bonnefoy M, Bordes S, et al. Effect of long-term omega 3 polyunsaturated fatty acid supplementation with or without multidomain intervention on cognitive function in elderly adults with memory complaints (MAPT): a randomised, placebo-controlled trial. Lancet Neurol. 2017 May;16(5):377-89.

111. Pérez LM, Enfedaque-Montes MB, Cesari M, Soto-Bagaria L, Gual N, Burbano MP, et al. A Community Program of Integrated Care for Frail Older Adults: +AGIL Barcelona. J Nutr Health Aging. 2019;23(8):710-6.

112. Kito N, Matsuo K, Ogawa K, Izumi A, Kishima M, Itoda M, et al. Positive Effects of "Textured Lunches" Gatherings and Oral Exercises Combined with Physical Exercises on Oral and Physical Function in Older Individuals: A Cluster Randomized Controlled Trial. J Nutr Health Aging. 2019;23(7):669-76.

113. Ruan Q, Xiao F, Gong K, Zhang W, Zhang M, Ruan J, et al. Prevalence of Cognitive Frailty Phenotypes and Associated Factors in a Community-Dwelling Elderly Population. J Nutr Health Aging. 2020;24(2):172-80.

114. Ge M, Zhang Y, Zhao W, Yue J, Hou L, Xia X, et al. Prevalence and Its Associated Factors of Physical Frailty and Cognitive Impairment: Findings from the West China Health and Aging Trend Study (WCHAT). J Nutr Health Aging. 2020;24(5):525-33.

115. Chye L, Wei K, Nyunt MSZ, Gao Q, Wee SL, Ng TP. Strong Relationship between Malnutrition and Cognitive Frailty in the Singapore Longitudinal Ageing Studies (SLAS-1 and SLAS-2). J Prev Alzheimers Dis. 2018;5(2):142-8.

116. Shimada H, Makizako H, Tsutsumimoto K, Doi T, Lee S, Suzuki T. Cognitive Frailty and Incidence of Dementia in Older Persons. J Prev Alzheimers Dis. 2018;5(1):42-8.

117. Halil M, Cemal Kizilarslanoglu M, Emin Kuyumcu M, Yesil Y, Cruz Jentoft AJ Cognitive aspects of frailty: mechanisms behind the link between frailty and cognitive impairment. J Nutr Health Aging. 2015 Mar;19(3):276-83.

118. Vellas B, Scrase D, Rosenberg GA, Andrieu S, Araujo de Carvalho I, Middleton LT. Editorial: WHO Guidelines on Community-Level Interventions to Manage Declines in Intrinsic Capacity: The Road for Preventing Cognitive Declines in Older Age? J Prev Alzheimers Dis. 2018;5(3):165-7.

119. Tavassoli N, Piau A, Berbon C, De Kerimel J, Lafont C, De Souto Barreto P, et al. Framework implementation of the inspire icope-care program in collaboration with the world health organization (who) in the occitania region. Journal of Frailty \& Aging [Internet]. 2019 Mar 1 [cited 2020 May 28]; Available from: https://www.jfrailtyaging. com/all-issues.html

120. Takeda, C., Guyonnet, S., Sumi, Y., Vellas. B., Araujo De Carvalho, I. Integrated Care for Older People and the Implementation in the INSPIRE Study. 2020;7(2):70-74.doi: 10.14283/jpad.2020.8.

121. Beard JR. Editorial: Linking Geroscience and Integrated Care to Reinforce Prevention J Prev Alzheimers Dis. 2020;7(2):68-9.

122. Guerville F, de Souto Barreto P, Giudici KV, Rolland Y, Vellas B, MAPT/DSA Group. Association of 3-Year Multidomain Intervention and Omega-3 Supplementation with Frailty Incidence. J Am Geriatr Soc. 2019 Aug;67(8):1700-6.

123. Muscedere J, Kim PM, Afilalo J, Balion C, Baracos VE, Bowdish D, et al. Proceedings of the Canadian Frailty Network Workshop: Identifying Biomarkers of Frailty to Support Frailty Risk Assessment, Diagnosis and Prognosis. Toronto, January 15, 2018 J Frailty Aging. 2019;8(3):106-16.

124. Rodriguez-Mañas L, Araujo de Carvalho I, Bhasin S, Bischoff-Ferrari HA, Cesari M, Evans W, et al. ICFSR Task Force Perspective on Biomarkers for Sarcopenia and Frailty. J Frailty Aging. 2020;9(1):4-8.

125. Bray NW, Jones GJ, Rush KL, Jones CA, Jakobi JM. Multi-Component Exercise with High-Intensity, Free-Weight, Functional Resistance Training in Pre-Frail Females: A Quasi-Experimental, Pilot Study. J Frailty Aging. 2020;9(2):111-7.

126. Cruz-Jentoft AJ, Woo J. Nutritional interventions to prevent and treat frailty. Curr Opin Clin Nutr Metab Care. 2019;22(3):191-5.

127. Dicks ND, Kotarsky CJ, Trautman KA, Barry AM, Keith JF, Mitchell S, et al Contribution of Protein Intake and Concurrent Exercise to Skeletal Muscle Quality with Aging. J Frailty Aging. 2020;9(1):51-6. 